\title{
Gemini Pyridinium Amphiphiles for the Synthesis and Stabilization of Gold Nanoparticles for Drug Delivery
}

\author{
María E. Alea-Reyes, ${ }^{\mathrm{a}, \mathrm{b}}$ Asensio González, ${ }^{\mathrm{a}}$ Ana C. Calpena, ${ }^{\mathrm{a}, \mathrm{b}, \mathrm{c}}$ David Ramos-López, Joaquín de \\ Lapuente $^{\mathrm{d}}$ and Lluïsa Pérez-García ${ }^{\mathrm{a}, \mathrm{b}, 1 *}$
}

a Departament de Farmacologia, Toxicologia i Química Terapèutica, Universitat de Barcelona, 08028 Barcelona, Spain, E-mail: mlperez@ub.edu; malearey7@alumnes.ub.edu; asensiogonzalez@ub.edu

${ }^{\mathrm{b}}$ Institut de Nanociència i Nanotecnologia IN2UB, Universitat de Barcelona, 08028 Barcelona, Spain

${ }^{c}$ Departament de Farmàcia i Tecnologia Farmacèutica i Fisicoquímica, Universitat de Barcelona, 08028 Barcelona, Spain, E-mail: anacalpena@ub.edu

${ }^{\mathrm{d}}$ Unitat de Toxicologia Experimental i Ecotoxicologia (UTOX-PCB), Baldiri i Reixac 10-12, 08028 Barcelona, Spain, E-mail:dramos@pcb.ub.es; jlapuente@pcb.ub.es

\footnotetext{
*Corresponding author at: Departament de Farmacologia, Toxicologia i Química Terapèutica, Universitat de Barcelona, 08028 Barcelona, Spain, Telephone: (+34) 934035849. Fax (+34) 934024539

E-mail address:mlperez@ub.edu

${ }^{1}$ Present address: School of Pharmacy, The University of Nottingham, University Park, Nottingham, NG7 2RD, United Kingdom

${ }^{2}$ Abbreviations: Gold nanoparticles (AuNPs). Centres Científics i Tecnològics de la Universitat de Barcelona (CCiT-UB). Infrared Spectroscopy (IR). Matrix Assisted Laser Desorption Ionization-Time of Flight Mass Spectrometry (MALDI-ToF-MS). High Resolution Mass Spectrometry (HRMS) by Electrospray Ionization (ESI). High-Resolution Transmission Electron Microscopy (HRTEM). Dynamic Light Scattering (DLS). Surface Plasmon Resonance (SPR). Thermogravimetric Analysis (TGA). The mouse fibroblast cell line (3T3/ NIH), the human liver carcinoma cell line (HepG2) and the human epithelial colorectal adenocarcinoma cell line (CaCo-2). Medium dissolution time (MDT) and area under curve (AUC).
} 


\begin{abstract}
Hypothesis

Gemini pyridinium-based amphiphiles can play a triple role as: gold nanoparticles (AuNPs) synthesis facilitator, particle stabilizer and anion recognition centre. The so formed nanoparticles should be able to bind and release anionic drugs.
\end{abstract}

\title{
Experiments
}

We describe (a) Synthesis, by a phase transfer method, of both new organic media and water soluble AuNPs using gemini-type surfactants based on bis-pyridinium salts as ligands, acting as transfer agents into organic media and also as nanoparticle stabilizers, (b) Examination of their stability in solution, (c) Chemical and physical characterization of the nanoparticles, (d) Toxicity data concerning both the bis-pyridinium ligands and the bis-pyridinium coated nanoparticles, and (e) Study of their ability for delivering anionic pharmaceuticals such as ibuprofen and piroxicam.

\section{Findings}

Pyridinium gemini-type surfactants show the ability to play multiple roles such as transfer agent and stabilizer, as well as ionophores: They are responsible for the preparation, stability, and delivery properties of these AuNPs, which gold core is stabilized by the anions present in the bispyridinium salts. The tetrahydropyridine resulting from the reduction of the pyridinium salt is capable of reduce gold, due to its spontaneous oxidation to the corresponding pyridinium salt, leading to the formation of stable AuNPs.

Keywords: Gemini pyridinium amphiphiles, tetrahydropyridines, gold nanoparticles, anionic drug encapsulation 


\section{Introduction}

Gold nanoparticles (AuNPs) are one of the most investigated metal nanoparticles.[1,2] They have attracted considerable interest in various applications such as catalysis, [3,4] medical diagnosis,[5] biological sensors,[6] drug delivery[7,8] and imaging.[9] Many types of ligands have been studied as stabilizers in the synthesis of organic and water soluble AuNPs: besides thiols, other examples found in the literature include thioether end-functionalized polymers,[10] dendrimers,[11] amino acid based amphiphiles,[12] peptides,[13] DNA,[14] and ionic liquids based on imidazolium salts.[15] In particular, the use of derivatives of pyridine such as 4-(dimethylamino)pyridine (DMAP),[16-18] dihydropyridine[19] and pyridinium salts[20,21] as stabilizing agents of AuNPs has been reported although the definitive stabilization mechanism is not yet fully established.

On the other hand, our group has reported previously the preparation and stabilization of monodisperse gold nanoparticles using gemini imidazolium-based amphiphiles.[22,23] These molecules show anion binding properties in solution, and therefore they play a unique triple role, acting as phase transfer agent of the gold salt during the synthesis, capping agent for the stabilization of the AuNPs, and binding agent for anionic molecules, resulting in a major simplification of the synthetic process and subsequent purification of the functional nanomaterial.[22] Furthermore, the ability of bis-imidazolium salts to complex anions,[24] particularly carboxylates, allowed the incorporation and delivery of a carboxylate-containing model drug.[22,25]

As a step forward in this research we have focused on the use of gemini amphiphiles based on bispyridinium salts in the synthesis of AuNPs, expecting that these molecules would expand the anion recognition ability of the nanomaterials. To test the AuNPs' ability to incorporate and release anionic molecules, two model drugs were used: ibuprofen and piroxicam, which are non-steroidal 
anti-inflammatory drugs widely used in inflammatory arthritis and osteoarthritis.[26] The gemini pyridinium salts used in this work are formed by two pyridinium rings linked by a 1,3dimethylenebenzene spacer. This spacer was chosen based in analogue compounds that contain pyridinium moieties rather than imidazolium. Therefore, to study the effect of the spacer (length and flexibility) lies beyond the scope of the present work.

Thus, we report here (a) a solution based preparation of new AuNPs (organic and water-soluble AuNPs) with bis-pyridinium amphiphilic ligands, which act both as transfer agents of gold into organic media and also as nanoparticle stabilizers, (b) the formation of AuNPs by reduction of Au

${ }^{3+}$ by the spontaneous oxidation of a bis-tetrahydropyridine amphiphile, (c) their chemical and physical characterization, including their stability in solution toward aggregation and ligand exchange, (d) toxicity data concerning both the bis-pyridinium ligands and the bis-pyridinium coated nanoparticles, (e) their molecular recognition ability toward piroxicam and ibuprofen, as models of anionic drugs, (f) in vitro studies of the ability of the new AuNPs for delivering anionic pharmaceuticals.

\section{Experimental Section}

\subsection{Materials}

Sodium hydrogen carbonate, sodium sulfate $\left(\mathrm{Na}_{2} \mathrm{SO}_{4}\right)$ and $6 \mathrm{~N}$ hydrochloric acid $(\mathrm{HCl})$ were purchased from Scharlau; sodium hydroxide $(\mathrm{NaOH})$ from Merck, 4-methylpyridine, 1,3bis(bromomethyl)benzene, 1-decanol, 1-octadecanol, 4-chloropyridine hydrochloride, hydrogen peroxide $\left(\mathrm{H}_{2} \mathrm{O}_{2}\right)$, sodium borohydride $\left(\mathrm{NaBH}_{4}\right)$, hydrogen tetrachloroaurate (III) ( $\left.\mathrm{HAuCl}_{4}\right)$, sodium citrate tribasic dihydrate, potassium bromide $(\mathrm{KBr})$, ibuprofen, piroxicam, tetraoctylammonium bromide, phosphate buffered saline (PBS) $\mathrm{pH}=7.4$ and 5.2 were purchased 
from Sigma-Aldrich. Metallic sodium and ammonia $20 \%$ were purchased from Panreac and hexa(ethylene glycol)alkyl thiol (HS-C $\left.{ }_{11}-(\mathrm{EG})_{6}-\mathrm{OH}\right)$ was purchased from Prochimia. Acetonitrile (MeCN), dichloromethane $\left(\mathrm{CH}_{2} \mathrm{Cl}_{2}\right)$, methanol $(\mathrm{MeOH})$, diethyl ether $\left(\mathrm{Et}_{2} \mathrm{O}\right)$, chloroform $\left(\mathrm{CHCl}_{3}\right)$, ethanol (EtOH), dimethyl sulfoxide (DMSO), tetrahydrofuran (THF), dimethylformamide (DMF), toluene, dimethylsulfoxide- $\mathrm{d}_{6}\left(\mathrm{CD}_{3}\right)_{2} \mathrm{SO}$ and chloroform-d $\left(\mathrm{CDCl}_{3}\right)$ were purchased from Sigma-Aldrich.

\subsection{Methods}

Melting points were measured by CTP-MP 300 hot-plate apparatus with ASTM 2C thermometer using crystal capillaries purchased from Afora. ${ }^{1} \mathrm{H}$ NMR: Varian Gemini $300(300 \mathrm{MHz})$, Varian Mercury 400 spectrometers (400 MHz) from Centres Científics i Tecnològics de la Universitat de Barcelona (CCiT-UB). ${ }^{13}$ C-NMR: Varian Mercury 400 (100 MHz) from CCiT-UB. NMR spectra were determined in $\mathrm{CDCl}_{3}$ or $\left(\mathrm{CD}_{3}\right)_{2} \mathrm{SO}$ with tetramethylsilane (TMS) as reference. The chemical shifts are expressed in parts per million ( $\mathrm{ppm}$ ) relative to the central peak of the solvent. Infrared Spectroscopy (IR): IR spectra were collected on a Thermo Nicolet Avatar 320 FT-IR spectrometer at room temperature in the range $4000-400 \mathrm{~cm}^{-1}$, in $\mathrm{KBr}$ pellets ( $1 \%$ of the samples). Elemental analysis was performed on a Thermo EA 1108 CHNS from CCiT-UB. Thin layer chromatography was performed on a Merck coated $\mathrm{F}_{254}$ silica gel plates. Column chromatography was carried on silica gel 60 (Merck 9385, 230-400 mesh). Matrix Assisted Laser Desorption Ionization-Time of Flight Mass Spectrometry (MALDI-ToF-MS) analysis were performed using a Voyager-DE-RP (Applied Biosystem, Framingham, USA) mass spectrometer, and High Resolution Mass Spectrometry (HRMS) were obtained by Electrospray Ionization (ESI) on a LC/MSD-ToF mass spectrometer (Agilent Technologies, 2006) from CCiT-UB. MS analysis was operated in the 
delayed extraction mode using 2,5-dihydroxybenzoic acid (DHB) as a matrix. UV absorption spectra were obtained using UV-1800 Shimadzu UV spectrophotometer, using quartz cuvettes with a $1 \mathrm{~cm}$ path length. Absorption spectra were determined in $\mathrm{CHCl}_{3}$ and $\mathrm{H}_{2} \mathrm{O}$. High-Resolution Transmission Electron Microscopy (HRTEM): The images were obtained using a JEOL JEM 2100 transmission electron microscope at $200 \mathrm{kV}$, from CCiT-UB. The protocol to prepare the samples for the HRTEM and experimental details of the cytotoxicity and genotoxicity, incorporation of drugs into AuNPs and the release study are explained in the Supplementary Material Section 1. The images were captured by a Mega view III Soft Imaging System camera, and the size of the nanoparticles gold core was measured with ImageJ.[27] The size of the nanoparticles was also determined by Dynamic Light Scattering (DLS) using a Zetasizer Nano ZS series (Malvern Instruments) from Departament de Farmàcia i Tecnologia Farmacèutica i Fisicoquímica, Universitat de Barcelona. XPS experiments were performed at Institut Català de Nanociència i Nanotecnologia (ICN2)-CSIC in a Phoibos 150 analyzer (SPECS GmbH, Berlin, Germany)) in ultra-high vacuum conditions (base pressure 5E-10 mbar) with a monochromatic aluminium Kalpha x-ray source (1486.74eV). ). The energy resolution as measured by the FWHM of the Ag $3 \mathrm{~d}_{5 / 2}$ peak for a sputtered silver foil was $0.58 \mathrm{eV}$. Thermogravimetric Analysis was performed on Mettler Toledo TGA/SDTA $851 \mathrm{e}$ from CCiT-UB, from $30^{\circ} \mathrm{C}$ to $700{ }^{\circ} \mathrm{C}$ with a heating rate of 10 ${ }^{\circ} \mathrm{C} \mathrm{min}^{-1}$. Capsules: crucible of aluminum $(100 \mu \mathrm{L})$ with perforated cap. Nitrogen was used as purgative gas in all measurements.

\subsection{Synthesis and characterization of the ligands $1 \cdot 2 \mathrm{Br}$ and 2}


1,3-Bis(4-octadecyloxy-1-piridiniomethyl)benzene dibromide $(1 \cdot 2 \mathrm{Br})$ : The synthesis of the precursor of $\mathbf{1 \cdot 2 B r}$ followed a modification of a protocol previously reported,[28] where metallic sodium $(1.86 \mathrm{~g}, 80 \mathrm{mmol})$ was added to 1 -octadecanol $(21.9 \mathrm{~g}, 80 \mathrm{mmol})$ at $110{ }^{\circ} \mathrm{C}$ for $2 \mathrm{~h}$. Then 4-chloropyridine hydrochloride $(4.95 \mathrm{~g}, 33 \mathrm{mmol})$ was added and the mixture was stirred for $72 \mathrm{~h}$ at $110{ }^{\circ} \mathrm{C}$. After cooling down to room temperature, water $(50 \mathrm{~mL})$ was added dropwise and the solution neutralized with $\mathrm{HCl} 6 \mathrm{~N}$. The aqueous phase was extracted with $\mathrm{CH}_{2} \mathrm{Cl}_{2}$ (4 x $25 \mathrm{~mL}$ ), and the organic phase was dried with anhydrous $\mathrm{Na}_{2} \mathrm{SO}_{4}$ and the solvent was evaporated in vacuum. The residue was purified using a silica gel column chromatography using $\mathrm{Et}_{2} \mathrm{O} / \mathrm{CH}_{2} \mathrm{Cl}_{2}(7: 3)$ as eluent, following by column chromatography in $\mathrm{CH}_{2} \mathrm{Cl}_{2} / \mathrm{MeOH}$ (9:1), obtaining 4octadecyloxypyridine $(2.66 \mathrm{~g}$, yield $23 \%)$ and used directly in next step.

A solution of 4-octadecyloxypyridine $(150 \mathrm{mg}, 0.43 \mathrm{mmol})$ in dry $\mathrm{MeCN}(13 \mathrm{~mL})$ was added dropwise during $1 \mathrm{~h}$ to a solution of 1,3-bis(bromomethyl)benzene (57 $\mathrm{mg}, 0.22 \mathrm{mmol}$ ) in dry MeCN (10 mL) and heated at $75{ }^{\circ} \mathrm{C}$ for $24 \mathrm{~h}$. After cooling down to room temperature, the suspension was filtered off, and the white solid was washed with MeCN (5 mL) and dried to afford 1.2Br $(1.80 \mathrm{~g}, 94 \%): \mathrm{mp}>300{ }^{\circ} \mathrm{C} .{ }^{1} \mathrm{H}-\mathrm{NMR}\left(300 \mathrm{MHz}, \mathrm{CDCl}_{3}, 25^{\circ} \mathrm{C}\right): \delta 9.76(\mathrm{~d}, J=7.5 \mathrm{~Hz}, 4 \mathrm{H}$, H-2', '6), 8.39 (s, 1H, Ar-H2), 7.69 (d, J=6.3 Hz, 2H, Ar-H 4, 6), 7.33 (d, J= 7.5 Hz, 4H, H- 3', 5'), $7.01(\mathrm{dd}, J=7.8 \mathrm{~Hz}, 1 \mathrm{H}, \mathrm{Ar}-\mathrm{H} 5), 5.92\left(\mathrm{~s}, 4 \mathrm{H}, \mathrm{N}-\mathrm{CH}_{2}\right), 4.21\left(\mathrm{t}, J=6.45 \mathrm{~Hz}, 4 \mathrm{H},\left(\mathrm{O}-\left(\mathrm{CH}_{2}\right)\right)\right.$, $1.25\left(\mathrm{~s}, 64 \mathrm{H}, 2\left(\mathrm{CH}_{2}\right)_{16}\right), 0.87\left(\mathrm{t}, J=6.6 \mathrm{~Hz}, 6 \mathrm{H},\left(\mathrm{CH}_{3}\right)\right) .{ }^{13} \mathrm{C}-\mathrm{NMR}\left(100 \mathrm{MHz}, \mathrm{CDCl}_{3}, 25{ }^{\circ} \mathrm{C}\right): \delta$ 170.4, (Py- C 4'), 146.9 (Py- C 2', 6'), 134.5 (Ar- C 1, 3), 131.3 (Ar- C2), 130.3 (Ar- C5), 130.1 (Ar- C 4, 6), 113.9 (Py- C 3', 5'), $71.4\left(\mathrm{O}_{-} \mathrm{CH}_{2}\right), 61.3\left(\mathrm{~N}-\mathrm{CH}_{2}\right), 31.8-22.6\left(\left(\mathrm{CH}_{2}\right)_{16}\right), 14.1\left(\mathrm{CH}_{3}\right)$. MALDI-ToF-MS m/z: $879.7(100 \%)[\mathrm{M}-\mathrm{Br}]^{+}, 797.7(85 \%)$ [M-2Br] $]^{+}, 530.4(30 \%)$ [M$\left.\mathrm{Br}\left(\mathrm{C}_{23} \mathrm{H}_{41} \mathrm{NO}\right)\right]^{+}, 450.5(20 \%)\left[\mathrm{M}-\left((2 \mathrm{Br}) \mathrm{C}_{23} \mathrm{H}_{41} \mathrm{NO}\right)\right]^{+}$. HMRS (ESI) m/z: $\left(\mathrm{C}_{54} \mathrm{H}_{90} \mathrm{~N}_{2} \mathrm{O}_{2} \mathrm{Br}_{2}-2 \mathrm{Br}\right)^{2+}$ 
calculated 399.3489 found 399.3496. Elemental analysis $\left(\mathrm{C}_{54} \mathrm{H}_{90} \mathrm{Br}_{2} \mathrm{~N}_{2} \mathrm{O}_{2} \cdot 1 \mathrm{H}_{2} \mathrm{O}\right.$ ): $\mathrm{N}$ (calculated 2.92 found 3.01) C (calculated 66.38 found 66.81) $\mathrm{H}$ (calculated 9.49 found 9.58 ).

1,3-Bis(4-octadecyloxy-1,2,5,6 tetrahydropyridylmethyl)benzene (2): A solution of $\mathrm{NaBH}_{4}(5$ $\mathrm{mg}, 0.13 \mathrm{mmol})$ in $\mathrm{H}_{2} \mathrm{O}(2 \mathrm{~mL})$ was added to a solution of $\mathbf{1} \cdot 2 \mathbf{B r}(25 \mathrm{mg}, 0.03 \mathrm{mmol})$ in $\operatorname{dry~} \mathrm{CH}_{2} \mathrm{Cl}_{2}$ $(2 \mathrm{~mL})$. The mixture was stirred during $1 \mathrm{~h}$ at room temperature. Then, the aqueous phase was extracted with $\mathrm{CH}_{2} \mathrm{Cl}_{2}(3 \times 5 \mathrm{~mL})$, and the organic phase was dried with anhydrous $\mathrm{Na}_{2} \mathrm{SO}_{4}$ and the solvent was evaporated in vacuum to afford 2 as a yellow oil $20 \mathrm{mg}, 88 \% .{ }^{1} \mathrm{H}-\mathrm{NMR}$ (300 $\left.\mathrm{MHz}, \mathrm{CDCl}_{3}, 25^{\circ} \mathrm{C}\right): \delta 7.32(\mathrm{~s}, 1 \mathrm{H}, \mathrm{Ar}-\mathrm{H} 2), 7.26$ (m, 3H, Ar-H 4, 5, 6), 4.54 (s, 2H, H5'), 3.61 (t, $J=7.06 \mathrm{~Hz}, 4 \mathrm{H},\left(\mathrm{O}-\left(\mathrm{CH}_{2}\right)\right), 3.56\left(\mathrm{~s}, 4 \mathrm{H}, \mathrm{N}-\mathrm{CH}_{2}\right), 3.03\left(\mathrm{~s}, 4 \mathrm{H}, \mathrm{H} 6^{\prime}\right), 2.59(\mathrm{t}, J=4.45 \mathrm{~Hz}, 4 \mathrm{H}, \mathrm{H}$ 2'), $2.20\left(\mathrm{~m}, 4 \mathrm{H}, 2\left(\mathrm{CH}_{2}\right)\right), 1.64\left(\mathrm{~m}, 4 \mathrm{H}, 2\left(\mathrm{CH}_{2}\right), 1.43-1.25\left(\mathrm{~s}, 56 \mathrm{H}, 2\left(\mathrm{CH}_{2}\right)_{14}\right), 0.88(\mathrm{t}, J=6.0 \mathrm{~Hz}\right.$, 6H, $\left.\mathrm{CH}_{3}\right)$. MALDI-ToF-MS m/z: $803.6(100 \%)[\mathrm{M}-1]^{+}, 454.3(70 \%)\left[\mathrm{M}-\left(\mathrm{C}_{31} \mathrm{H}_{52} \mathrm{NO}\right)\right] . \mathrm{HMRS}$ (ESI) $\mathrm{m} / \mathrm{z}:\left(\mathrm{C}_{54} \mathrm{H}_{96} \mathrm{~N}_{2} \mathrm{O}_{2}\right)$ calculated 804.75 found 805.75 .

\subsection{Synthesis and characterization of AuNPs}

\subsubsection{Synthesis of $1 \cdot$ AuNPs with the bis-pyridinium salt $1 \cdot 2 \mathrm{Br}$}

A solution of $\mathrm{HAuCl}_{4}(11.8 \mathrm{mg}, 0.03 \mathrm{mmol})$ in water $(0.5 \mathrm{~mL})$ and a $1 \%$ solution of trisodium citrate dihydrate $(15 \mathrm{mg}, 0.05 \mathrm{mmol})$ in water $(1.5 \mathrm{~mL})$ were added to boiling water $(10 \mathrm{~mL})$. Heating was continued for 15 min. during which time the solution changed colour from pale yellow to red. The reaction flask was allowed to cool to room temperature. Then, an aqueous solution of these AuNPs $(8 \mathrm{~mL})$ was mixed with a solution of ligand $\mathbf{1} \cdot \mathbf{2 B r}(24 \mathrm{mg}, 0.025 \mathrm{mmol})$ in $\mathrm{CHCl}_{3}(8$ $\mathrm{mL}$ ). The biphasic mixture was stirred for $24 \mathrm{~h}$ in the dark at room temperature. The phases were separated and the solvent of the organic phase was removed in a rotary evaporator, and the residue washed using centrifugation in $\mathrm{EtOH}(3 \times 1 \mathrm{~mL})$, to give 1•AuNPs. 


\subsubsection{Synthesis of $2 \cdot$ AuNPs with the bis-pyridinium salt $1 \cdot 2 \mathrm{Br}$}

An aqueous solution of $\mathrm{HAuCl}_{4}(8.8 \mathrm{mg}, 0.026 \mathrm{mmol})$ in water $(2 \mathrm{~mL})$ was mixed with a solution of $1.2 \mathrm{Br}(50 \mathrm{mg}, 0.052 \mathrm{mmol})$ in $\mathrm{CHCl}_{3}(2 \mathrm{~mL})$. After $1 \mathrm{~h}$, a solution of $\mathrm{NaBH}_{4}(4.9 \mathrm{mg}, 0.13$ mmol) in water $(2 \mathrm{~mL})$ was slowly added. The stirring continued for $4 \mathrm{~h}$ in the dark at room temperature. The organic phase of the resulting dark red solution was separated and the solvent was removed in a rotary evaporator, and the residue washed using centrifugation in $\mathrm{EtOH}(5 \times 1$ $\mathrm{mL}$ ), to afford $\mathbf{2} \cdot$ AuNPs.

\subsubsection{Synthesis of $3 \cdot$ AuNPs and $4 \cdot$ AuNPs using the bis-pyridinium salt $1 \cdot 2 \mathrm{Br}$ and the thiol HS-C11-(EG)6-OH}

A solution of $\mathrm{HAuCl}_{4}(3.6 \mathrm{mg}, 0.009 \mathrm{mmol})$ in water $(0.5 \mathrm{~mL})$ was added to a stirred solution of 1.2Br $(4.3 \mathrm{mg}, 0.005 \mathrm{mmol})$ in $\mathrm{CHCl}_{3}(0.5 \mathrm{~mL})$. Then, a solution of the thiol $\mathrm{HS}-\mathrm{C}_{11}-(\mathrm{EG})_{6}-\mathrm{OH}$ (2.1 mg, $5 \mu \mathrm{mol})$ in $\mathrm{CHCl}_{3}(0.5 \mathrm{~mL})$ was added. An excess of $\mathrm{NaBH}_{4}(5.1 \mathrm{mg}, 0.14 \mathrm{mmol})$ in water $(1 \mathrm{~mL})$ was added dropwise to the mixture. The stirring continued for $24 \mathrm{~h}$ in the dark at room temperature. AuNPs were obtained in both phases (organic and aqueous phase). The water-soluble AuNPs were named 3-AuNPs and the organic-soluble AuNPs were named 4·AuNPs. The phases were separated and the solvent of aqueous phase $(3 \cdot$ AuNPs $)$ and organic phase $(4 \cdot$ AuNPs $)$ was removed in a rotary evaporator, and the residues washed using centrifugation in EtOH (5 x $1 \mathrm{~mL})$.

\subsubsection{Synthesis of $2^{\prime} \cdot$ AuNPs with the tetrahydropyridine 2 .}

A solution of $2(50 \mathrm{mg}, 62 \mu \mathrm{mol})$ in $\mathrm{CHCl}_{3}(2 \mathrm{~mL})$ was added to a solution of $\mathrm{KBr}(15.3 \mathrm{mg}, 0.13$ mmol) in water $(2 \mathrm{~mL})$. Then a solution of $\mathrm{HAuCl}_{4}(1.8 \mathrm{mg}, 0.005 \mathrm{mmol})$ in water $(2 \mathrm{~mL})$ was 
added dropwise to the mixture. The stirring continued for $3 \mathrm{~h}$ in the dark at room temperature. The phases were separated and the organic solvent was removed in a rotary evaporator, and the residue washed using centrifugation in EtOH $(5 \times 1 \mathrm{~mL})$, to afford $\mathbf{2}^{\prime} \cdot$ AuNPs.

\section{Results and Discussion}

The compounds synthesized in this work are bis-pyridinium salts connected through a 1,3-xylyl spacer; the pyridinium moieties bear chains of different length: $\mathbf{1} \cdot \mathbf{2 B r}$ (18 carbon atoms) (Figure 1), $\mathbf{3} \cdot \mathbf{2 B r}(10$ carbon atoms) and $\mathbf{4} \cdot \mathbf{2} \mathbf{B r}$ (1 carbon atom) (see Supplementary Material Figure S1), to assess the influence of the chain length on the synthesis and stability of the AuNPs where they will be incorporated. The three bis-pyridinium salts $1 \cdot 2 \mathrm{Br}, 3 \cdot 2 \mathrm{Br}$ and $4 \cdot 2 \mathrm{Br}$ were synthesized in good yield (see Supplementary Material Scheme S1). Salts $\mathbf{1 \cdot 2 B r}$ and $3 \cdot 2 \mathbf{B r}$ were obtained in two steps by reaction of 4-chloropyridine hydrochloride with aliphatic alcoxides, either from 1octadecanol or 1-decanol, affording the corresponding alkoxypyridines,[28] which were the limiting step, since they were difficult to purify. The alkoxypyridines reacted with 1,3bis(bromomethyl)benzene to afford $\mathbf{1 \cdot 2 B r}(94 \%)$ and $\mathbf{3 \cdot 2 B r}(83 \%)$, respectively. Also, the tetrahydropyridine 2 was obtained in $88 \%$ in yield by treatment of bis-pyridinium salt $\mathbf{1} \cdot \mathbf{2 B r}$ with an excess of $\mathrm{NaBH}_{4}$ (Figure 1 and Scheme $\mathrm{S} 1$ in Supplementary Material). The bis-pyridinium salt 4.2Br was obtained in $97 \%$ in yield by reaction of 4-methylpyridine with 1,3bis(bromomethyl)benzene (Scheme S1 in Supplementary Material). These newly synthesized bis-

pyridinium salts $1 \cdot 2 \mathrm{Br}, 3 \cdot 2 \mathrm{Br}$ and $4 \cdot 2 \mathrm{Br}$ and the tetrahydropyridine 2 were characterized by ${ }^{1} \mathrm{H}$ and ${ }^{13} \mathrm{C}-\mathrm{NMR}$ spectroscopy, MALDI-ToF-MS, IR and elemental analysis. The results of the different techniques used for the characterization of the ligands are shown in the Supplementary Material (Figure S2-S21). 


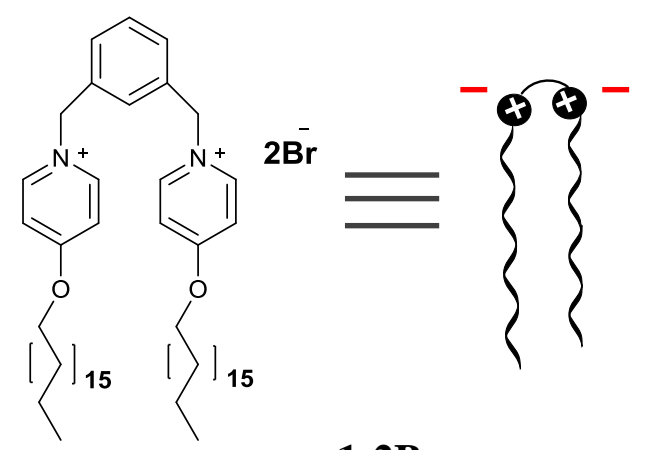

$1 \cdot 2 \mathrm{Br}$

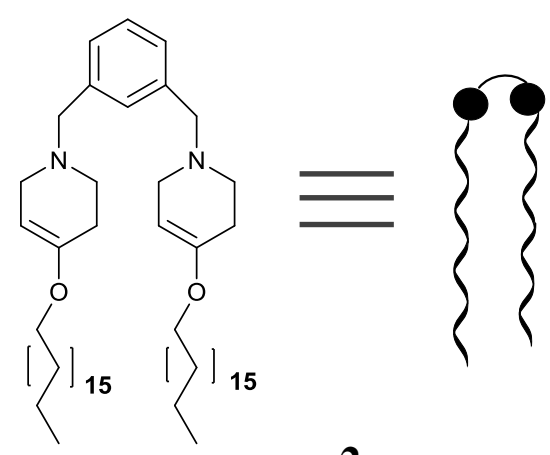

2

$-\mathbf{B r}^{-}$

Figure 1. Structures of compounds $\mathbf{1} \cdot \mathbf{2 B r}$ and $\mathbf{2}$ and their respective cartoons.

Figure (1.5-column)

\subsection{Synthesis of AuNPs using $1 \cdot 2 \mathrm{Br}$ and the tetrahydropyridine 2}

The schematic representation of the different AuNPs are shown in Scheme 1 and their synthesis method was selected depending of the solubility of the ligands $\mathbf{1} \cdot \mathbf{2 B r}$ and $\mathbf{2}$. The different experiments for their preparation are summarized in Table 1.

Firstly, we synthesized AuNPs using the bis-pyridinium salt $\mathbf{1 \cdot 2 B r}$ to study their capacity as stabilizer agent. Thus, 1·AuPs were obtained by a two-step procedure, consisting of the preparation of citrate stabilized NPs (using a modification of Turkevich method[29]), followed by mixing with a solution of the ligand $\mathbf{1 \cdot 2 B r}$ for $24 \mathrm{~h}$ (Table 1 entry 1 ). The characterization of 1•AuNPs (see later) indicates the presence of a bis-pyridinium salt coating the stabilized gold nanoparticles.

On the other hand, the synthesis following a modification of AuNPs using the same bis-pyridinium salt $1 \cdot 2 \mathrm{Br}$ as stabilizing agent and the biphasic Brust-Schiffrin protocol[30] resulted in a red solution, the so-formed AuNPs are named 2-AuNPs here (Table 1, entry 2). In this case, the reducing agent $\mathrm{NaBH}_{4}$ converts the pyridinium salt to the tetrahydropyridine $\mathbf{2}$, and therefore a 
mixed coating is expected for $\mathbf{2} \cdot \mathbf{A u N P s}$ (Scheme 1). These results confirm the capacity of $\mathbf{1} \cdot \mathbf{2 B r}$ as stabilizer agent as well as transfer agent in the synthesis of the $\mathbf{1} \cdot$ AuNPs and $\mathbf{2} \cdot \mathbf{A u N P s}$. Additionally, the stability of $\mathbf{2} \cdot$ AuNPs was determined in solution at room temperature and under reflux in three different solvents $\left(\mathrm{CHCl}_{3}\right.$, THF and toluene), by means of $\mathrm{UV}$-vis absorption spectroscopy. No obvious change in the shape of the maximum in the plasmon resonance peak was observed, which indicates that the prepared $\mathbf{2} \cdot$ AuNPs are stable (Supplementary Material Section 3 Table S1).

One concern during the synthesis of these AuNPs is the chemical integrity of the bis-pyridinium salt $1 \cdot 2 \mathrm{Br}$ under the reaction conditions used, especially in the presence of $\mathrm{NaBH}_{4}$ as the reducing agent, because the reduction could lead to the formation of tetrahydropyridine species that could influence the stability of the AuNPs. The mechanism of the reduction of pyridinium salts by sodium borohydride to give tetrahydropyridine and piperidine derivatives has been well established.[31,32] It is known that dihydropyridines can act as coatings in the formation of stable gold nanoparticles,[19] while for tetrahydropyridines, to the best of our knowledge, have not been reported yet.

To obtain water soluble AuNPs, with potential to be used in biomedical applications, some attempts were made to use both ligands in a monophasic system, but no AuNPs could be obtained, and therefore we chose to use a biphasic system adapted from the Brust-Schiffrin method. Basically, the AuNPs preparation consisted of mixing of the gemini pyridinium based amphiphilic ligand $\mathbf{1} \cdot 2 \mathrm{Br}$ and a thiolated polyethyleneglycol derivative $\mathrm{HS}_{-} \mathrm{C}_{11}-(\mathrm{EG})_{6}-\mathrm{OH}$ in $\mathrm{CHCl}_{3}$ for the formation and coating of AuNPs, and then adding the aqueous $\mathrm{HAuCl}_{4}$ solution and the reducing agent $\left(\mathrm{NaBH}_{4}\right)$. Following this method, it was possible to obtain two types of AuNPs: Watersoluble AuNPs named 3·AuNPs and organic-soluble AuNPs named 4-AuNPs (Table 1, entry 3). 
The different hydrophilicity of $\mathbf{3} \cdot$ AuNPs and $4 \cdot$ AuNPs may originate on the relative proportion of both stabilizers, obviously with $\mathbf{3} \cdot$ AuNPs having a higher content on $\mathrm{HS}_{-} \mathrm{C}_{11}-(\mathrm{EG})_{6}-\mathrm{OH}$, but the exact proportion of each could not be exactly determined. The obtained 3-AuNPs and 4-AuNPs will allow to study the incorporation and interaction with different anionic drugs such as ibuprofen and piroxicam and their respective sodium salts (see later).

To confirm which species, either pyridinium salt $\mathbf{1} \cdot \mathbf{2 B r}$ or its reduced form $\mathbf{2}$, is stabilizing the gold surface, we encompassed different experiments (Table 1 entries 4 and 5). First, we attempted the synthesis of AuNPs using the tetrahydropyridine 2 following a modification of the BrustSchiffrin method but in the absence of the reducing agent $\mathrm{NaBH}_{4}$. Under these conditions, the bistetrahydropyridine 2 is capable of reducing $\mathrm{Au}^{+3}$ to $\mathrm{Au}^{0}$, concomitantly to its spontaneous oxidation to the corresponding bis-pyridinium salt, leading to the formation of nanoparticles, which were unstable in solution as indicated by the formation of a dark precipitate after $24 \mathrm{~h}$ (Table 1, entry 4). However, when the tetrahydropyridine 2 was used in the presence of an excess of $\mathrm{KBr}$ (Table 1 , entry 5), stable $\mathbf{2}^{\prime} \cdot$ AuNPs soluble in organic solvents were obtained. The stabilization of the metallic core by reduced $\mathbf{2}$ is proven by the fact that nanoparticles are not stable when synthetized from 2 with no addition of an excess of $\mathrm{KBr}$. Additionally, the excess of pyridinium salts $\mathbf{1} \cdot \mathbf{2 B r}$ that are not coating the AuNPs, and therefore remains free in solution, is rapidly reduced to tetrahydropyridine 2 by action of the $\mathrm{NaBH}_{4}$ used as reducing agent, likely resulting in a formation of a bilayer around the pyridinium salts, although the exact disposition of $\mathbf{2}$ is not exactly determined. Due to the fact that the tetrahydropyridine does not have charges, these AuNPs are not water-soluble. If a $\mathbf{1} \cdot \mathbf{2} \mathbf{B r}$ bilayer was formed, the AuNPs would be water-soluble. 


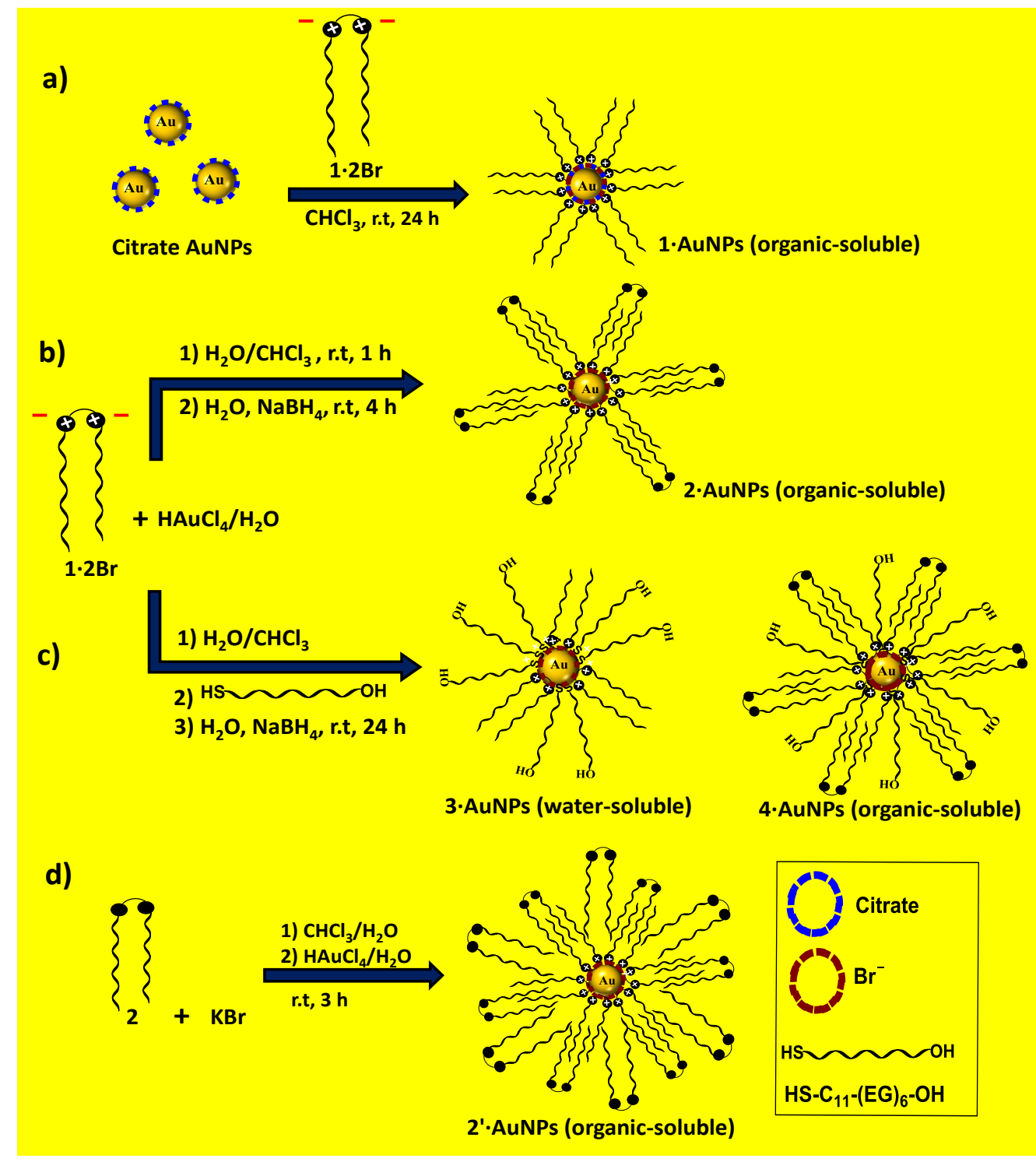

Scheme 1. Schematic representation of the synthesis of the gold nanoparticles: a) 1・AuNPs, b) 2•AuNPs, c) 3•AuNPs, d) 4·AuNPs an d) 2'AuNPs. Scheme (2-column)

These experiments indicate that the stabilizing species around the gold core in the AuNPs is the ion pair formed by either bromide or citrate ions, attached to the gold particle surfaces, and the cationic surfactant head groups (gemini pyridinium salt) surrounding the anion layer by electrostatic interactions. This conclusion arises from the fact that when no enough bromide ions anions are present, i.e. when using only the tetrahydropyridine 2, the obtained AuNPs are not 
sufficiently stable and flocculate. These results are in agreement with previous reports on the interaction of anions with a solution of metallic nanoparticles, and the ions' role in the stabilization of metal nanoparticles.[33] All the above indicates that for the synthesis of stable AuNPs based on bis-pyridinium salts the presence of the anions in their structure is critically important.

On the other hand, to study the influence of the length chain of the ligands on the stabilization of the AuNPs, we selected bis-pyridinium salts with shorter hydrocarbon chains: $\mathbf{3} \cdot \mathbf{2 B r}$ and $\mathbf{4} \cdot \mathbf{2 B r}$ (see Supplementary Material Figure S1). The synthesis of AuNPs using the bis-pyridinium salt 3.2Br was attempted following a modification of the Brust-Schiffrin method[30] (see Supplementary Material Section 4 Table S2, entry 6). In the case of $\mathbf{4} \cdot \mathbf{2 B r}$, the preparation of the AuNPs was attempted by a modification of the Turkevich method[29] using different reduction agents such as $\mathrm{NaBH}_{4}[34], \mathrm{H}_{2} \mathrm{O}_{2}[35,36]$ or citrate[29] (see Supplementary Material Table S2, entries $7-10$ ). In all cases, using $\mathbf{3} \cdot \mathbf{2 B r}$ or $\mathbf{4} \cdot \mathbf{2 B r}$ did not yield any AuNPs, as no formation of the typical red solution was observed, and a precipitate was visible in some cases. Clearly, the length of the chain of the bis-pyridinium salt, 18 carbon atoms in $\mathbf{1} \cdot \mathbf{2 B r}$ is decisive for the amphiphile to act as promoter agent, and thus to successfully generate AuNPs. Consequently, the use of $\mathbf{3} \cdot \mathbf{2 B r}$ and $4 \cdot 2 B r$ for the synthesis of AuNPs was not further studied.

Table 1. Experiments for the synthesis of AuNPs with bis-pyridinium salts $\mathbf{1} \cdot \mathbf{2 B r}$ and the tetrahydropyridine 2 .

\begin{tabular}{ccccccc}
\hline Entry & $\mathbf{S}^{\mathbf{a}}$ & $\mathbf{R A}^{\mathbf{b}}$ & $\mathbf{A u} \mathbf{S}^{\mathbf{a}}: \mathbf{R A}^{\mathbf{b}}$ & $\begin{array}{c}\mathbf{R C}^{\mathbf{c}} \\
\mathbf{T}\left({ }^{\circ} \mathbf{C}\right) / \text { solvent }\end{array}$ & AuNPs & Aspect \\
\hline $\mathbf{1}$ & $\mathbf{1 \cdot 2 B r}$ & Citrate & $1: 8: 12$ & $\mathrm{r.t} / \mathrm{CHCl}_{3} ; \mathrm{H}_{2} \mathrm{O}$ & $\mathbf{1 \cdot A u N P s}$ & $\begin{array}{c}\text { red } \\
\text { solution }\end{array}$ \\
\hline
\end{tabular}




\begin{tabular}{|c|c|c|c|c|c|c|}
\hline 2 & $1 \cdot 2 \mathrm{Br}$ & $\mathrm{NaBH}_{4}$ & $1: 2: 5$ & r.t/ $/ \mathrm{CHCl}_{3} ; \mathrm{H}_{2} \mathrm{O}$ & $2 \cdot A u N P s$ & $\begin{array}{c}\text { red } \\
\text { solution }\end{array}$ \\
\hline \multirow[t]{2}{*}{3} & $1 \cdot 2 B r^{d}$ & $\mathrm{NaBH}_{4}$ & 1:0.5:15 & r.t/ $/ \mathrm{CHCl}_{3} ; \mathrm{H}_{2} \mathrm{O}$ & 3·AuNPs & $\begin{array}{c}\text { red } \\
\text { solution }\end{array}$ \\
\hline & $1 \cdot 2 B^{d}$ & $\mathrm{NaBH}_{4}$ & 1:0.5:15 & r.t/ $/ \mathrm{CHCl}_{3} ; \mathrm{H}_{2} \mathrm{O}$ & $4 \cdot A u N P s$ & $\begin{array}{c}\text { red } \\
\text { solution }\end{array}$ \\
\hline 4 & 2 & - & $1: 2: 0$ & r.t/ $/ \mathrm{CHCl}_{3}$ & - & $\begin{array}{c}\text { dark } \\
\text { precipitate }\end{array}$ \\
\hline 5 & $2^{\mathrm{e}}$ & - & $1: 12: 0$ & r.t/ $/ \mathrm{CHCl}_{3} ; \mathrm{H}_{2} \mathrm{O}$ & $2^{\prime} \cdot$ AuNPs & $\begin{array}{c}\text { red } \\
\text { solution }\end{array}$ \\
\hline
\end{tabular}

${ }^{a}$ S: Stabilizer. ${ }^{b}$ RA: Reducing Agent. ${ }^{c}$ RC: Reaction conditions. ${ }^{\mathrm{d}}$ In presence of HS-C $\mathrm{C}_{11-}(\mathrm{EG})_{6^{-}}$ $\mathrm{OH}$ respect to $\mathrm{Au}^{0}$. The number of moles of $\mathbf{1} \cdot \mathbf{2} \mathbf{B r}$ plus HS-C ${ }_{11}-(\mathrm{EG})_{6}-\mathrm{OH}$ is equivalent to the total amount of $\mathbf{1} \cdot \mathbf{B r r}$ used in previous experiments. ${ }^{\mathrm{e}}$ In presence of an excess of $\mathrm{KBr}$ respect to $\mathrm{Au}^{0}$. Table (1.5-column)

\subsection{Characterization of AuNPs from 1.2Br and the tetrahydropyridine 2}

UV-vis absorption spectroscopy of $\mathbf{1} \cdot \mathbf{A u N P s}-\mathbf{4} \cdot \mathbf{A u N P s}$ and $\mathbf{2}^{\prime} \cdot \mathbf{A u N P s}$ in $\mathrm{CHCl}_{3}$ as well as 3-AuNPs in water showed the typical surface plasmon resonance (SPR) peaks of gold colloids between 510 and $526 \mathrm{~nm}$ (Figure 2 black, red, dark blue, light blue and green line, respectively) which is responsible for their typically coloured solutions. The different SPR peaks obtained for the synthesized $1 \cdot$ AuNPs-4 $\cdot$ AuNPs and $\mathbf{2}^{\prime} \cdot$ AuNPs, may be due to the selected synthesis method in each GNP and their varied composition. 


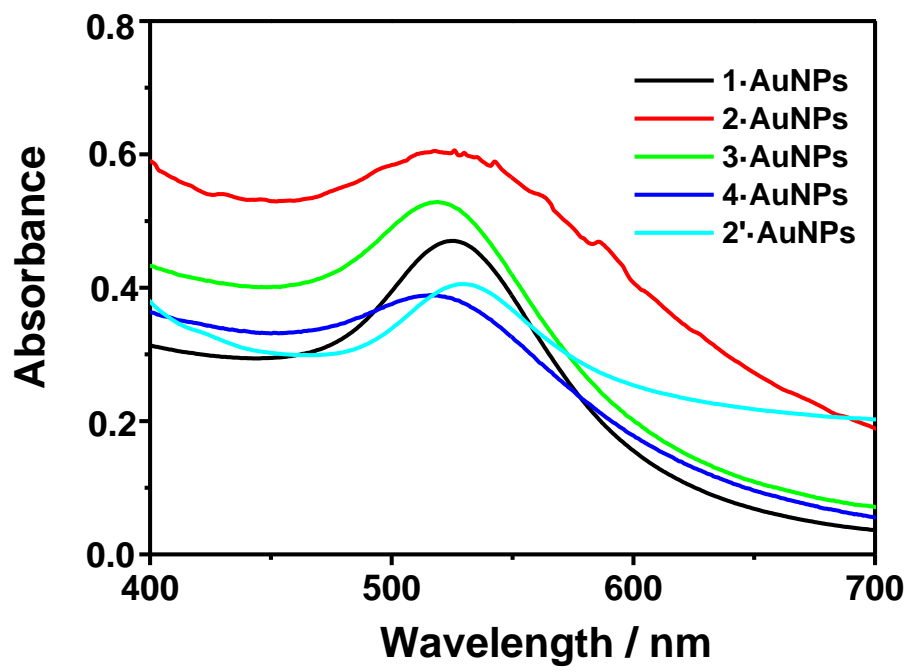

Figure 2. UV-vis absorption spectra of the 1'AuNPs-4·AuNPs and 2'・AuNPs. Figure (1.5-column)

High-Resolution Transmission Electron Microscopy (HRTEM). 1·AuNPs-4·AuNPs and 2' AuNPs were characterized using HRTEM to study their morphology and their size distribution. The samples observed by HRTEM were prepared by depositing onto a carbon-coated copper grid the solutions of AuNPs with concentration range between $4 \times 10^{-4}-5 \times 10^{-2} \mu \mathrm{M}$. Figure 3 shows the micrographs obtained for $\mathbf{1} \cdot \mathbf{A u N P s}-\mathbf{4} \cdot \mathbf{A u N P s}$ and $\mathbf{2} \cdot \mathbf{A u N P s}$ and their respective histograms. In all cases, the nanoparticles display a spheroidal shape and low polydispersity (Table 2). The samples of 1•AuNPs showed the biggest size and lowest polydispersity, which may be due to the selected synthesis method using a Turkevich protocol. Colloids $2 \cdot$ AuNPs and 4•AuNPs showed the highest polydispersity with an average size between 5 and $17 \mathrm{~nm}$, while in the cases of 3·AuNPs and 2'-AuNPs an average size between 9-13 nm was observed (Table 2). 


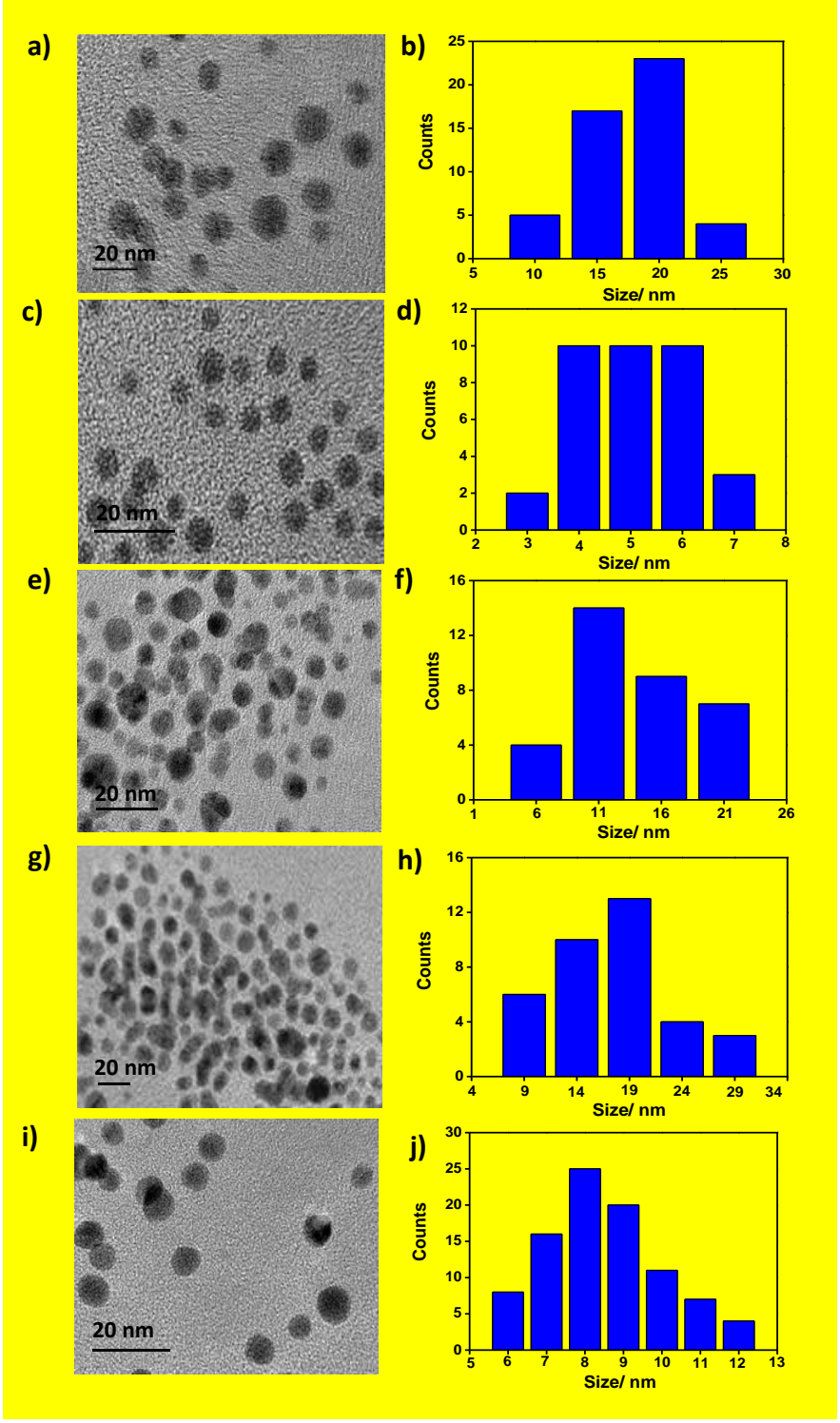

Figure 3. HRTEM micrographs of a) 1·AuNPs c) $\mathbf{2} \cdot$ AuNPs, e) 3·AuNPs, g) $4 \cdot$ AuNPs and i) $\mathbf{2}^{\prime} \cdot$ AuNPs and, b), d), f), h) and j) are their corresponding histograms. In all cases, the number of particle counts was higher than 35. Figure (1.5-column)

Dynamic Light Scattering (DLS). The size of 1·AuNPs, 2•AuNPs, 3·AuNPs, 4·AuNPs and 2'A AuNPs was also measured using DLS. These AuNPs proved stable in solution and have low polydispersity index as shown in the Table 2. The average size measured was between 11.3-23.5 $\mathrm{nm}$. These results imply a slightly higher diameter than that observed by HRTEM, in agreement 
with the fact that this technique measures the hydrodynamic size of the particles, in contrast with HRTEM that only gives us the gold core size, because no contrast agent was used and the ligands used are transparent to the electron beam compared with the gold. Thus, the size measured by DLS gives the diameter that includes not only the core but also the alkyl chains of the ligands. 1•AuNPs showed the highest value of size $(23.5 \mathrm{~nm})$, this result may be due to the selected synthesis method, as it is known that the AuNPs synthesized by Turkevich method present a bigger size than the AuNPs synthesized by Brust-Schiffrin method. On the other hand, the values of the size obtained by DLS were similar for $\mathbf{2} \cdot$ AuNPs and $\mathbf{2}^{\prime} \cdot$ AuNPs nanoparticles, this may be because both have a similar composition, while in the case of $3 \cdot$ AuNPs and 4 AuNPs were bigger, this may be due to the presence of S-PEG on the surface of AuNPs, which leads to increase the diameter of the nanoparticles.

NMR spectroscopy. NMR spectroscopy was used to complement the information about the species coating the different AuNPs, and the results are in good agreement with those observed by MALDI-ToF-MS. The ${ }^{1} \mathrm{H}$ NMR spectra of $\mathbf{1} \cdot \mathbf{A u N P s}$, acquired in $\mathrm{CDCl}_{3}$ at room temperature exhibit signals corresponding to the bis-pyridinium salt $\mathbf{1} \cdot \mathbf{2 B r}$ (see Supplementary Material Figure S22). In contrast, in the cases of the $2 \cdot$ AuNPs and $2 \cdot$ AuNPs, the signals corresponding to the tetrahydropyridine $\mathbf{2}$ were observed (see Supplementary Material Figure S23 and S24, respectively).

Table 2. Average size measured by HRTEM, DLS and Pdi for 1•AuNPs-4•AuNPs and 2'・AuNPs. 


\begin{tabular}{|c|c|c|c|}
\hline Sample & $\begin{array}{l}\text { Z-average }^{\mathrm{a}}(\mathrm{nm}) / \\
\text { HRTEM }^{\mathrm{b}} \pm \mathrm{SD}^{\mathrm{c}}\end{array}$ & $\begin{array}{c}\text { Z-average }^{\mathrm{a}}(\mathrm{nm}) / \\
\text { DLS }^{\mathrm{d}}\end{array}$ & $\mathbf{P d i}^{\mathbf{e}}$ \\
\hline $1 \cdot A u N P s$ & $18.3 \pm 0.5$ & 23.5 & 0.08 \\
\hline $2 \cdot A u N P s$ & $5.8 \pm 1.3$ & 11.3 & 0.26 \\
\hline 3·AuNPs & $13.5 \pm 2.7$ & 17.3 & 0.13 \\
\hline $4 \cdot A u N P s$ & $16.5 \pm 2.9$ & 21.2 & 0.25 \\
\hline $2^{\prime} \cdot$ AuNPs & $9.7 \pm 0.5$ & 13.7 & 0.17 \\
\hline
\end{tabular}

a Average size measured. ${ }^{\mathrm{b}}$ High-Resolution Transmission Electron Microscopy. ${ }^{\mathrm{c}}$ Standard deviation. ${ }^{\mathrm{d}}$ Dynamic Light Scattering. ${ }^{\mathrm{e}}$ Polydispersity index calculated by DLS. Table (1.5-column)

Matrix Assisted Laser Desorption Ionization-Time of Flight Mass Spectrometry (MALDI-ToFMS). This technique was used to study the coating of $1 \cdot$ AuNPs-4 $\cdot$ AuNPs and $\mathbf{2}^{\prime} \cdot \mathbf{A u N P s}$, and the results are shown in Table 3 (see also Supplementary Material Table S3 and Figure S25-S29, respectively). The spectra were recorded using DHB as the matrix. Despite precedents from the literature reports, $[22,23,25]$ on bis-imidazolium coated nanoparticles, the experimental conditions for recording sufficiently informative spectra were difficult to find. As we can see in Table 3 and Table S3 see Supplementary Material, all nanoparticles but 1·AuNPs have multicomponent coatings. In the case of $\mathbf{2} \cdot$ AuNPs and $\mathbf{2}^{\prime} \cdot$ AuNPs there is indication of the presence of both ligands $\mathbf{1} \mathbf{2 B r}$ or 2 , peaks arising from the tetrahydropyridine 2 being the most abundant, together with peaks resulting from the fragmentation of $\mathbf{1 \cdot 2} \mathbf{B r}$ (see Supplementary Material Table S3). These results can be explained in terms of the redox processes taking place during the synthesis of the AuNPs leading to the existence of both species in the mixed coatings, i.e. reduction of $\mathbf{1} \cdot \mathbf{2 B r}$ by $\mathrm{NaBH}_{4}$ in the case of $\mathbf{2} \cdot \mathbf{A u N P s}$, or spontaneous oxidation of $\mathbf{2}$ in the case of $\mathbf{2}^{\prime} \cdot \mathbf{A u N P s}$. Obviously, 
for $\mathbf{1}$ AuNPs, synthesized using citrate as the reducing agent, only peaks associated to the bispyridinium salt $\mathbf{1} \cdot \mathbf{2 B r}$ can be observed; specifically, peaks corresponding to its the molecular ion (m/z 957.6) (Table 3) or peaks resulting from its fragmentation (Table S3 in the Supplementary Material); the fragments reveal complexation to gold, indicating close proximity to the surface of the nanoparticle metallic core. For multicomponent colloids 3•AuNPs and 4·AuNPs the most abundant peaks indicate the presence of both $\mathbf{1} \cdot \mathbf{2 B r}$ and the thiolated polyethyleneglycol derivative as the predominant species, although in the case of $\mathbf{4} \cdot \mathbf{A u N P s}$, the tetrahydropyridine $\mathbf{2}$ was also present, something that could explain the higher hydrophobicity of these nanoparticles because of the absence of charge in the reduced surfactant.

Table 3. Positive-Ion Mode MALDI-ToF-MS for the AuNPs $\mathbf{1} \cdot \mathbf{A u N P s}-\mathbf{4} \cdot \mathbf{A u N P s}$ and $\mathbf{2} \cdot$ 'AuNPs using DHB as matrix.

\begin{tabular}{|c|c|c|c|}
\hline \multicolumn{4}{|c|}{$\operatorname{ions}^{a}(m / z, \%)$} \\
\hline AuNPs & {$\left[\mathrm{M}^{\mathrm{b}}-1 \mathrm{H}\right]^{+}$} & {$\left[\mathrm{M}^{\mathrm{c}}-\mathrm{H}\right]^{+}$} & {$\left[\mathrm{M}^{\mathrm{d}}+\mathrm{Na}^{+}\right]^{+}$} \\
\hline 1·AuNPs & $957.6(45 \%)$ & & \\
\hline 2.AuNPs & & $803.8(100 \%)$ & \\
\hline 3·AuNPs & $957.6(90 \%)$ & & $491.3(100 \%)$ \\
\hline 4.AuNPs & $957.6(100 \%)$ & $803.8(45 \%)$ & $491.3(75 \%)$ \\
\hline $2^{\prime} \cdot$ AuNPs & & $803.8(100 \%)$ & \\
\hline
\end{tabular}

X-ray Photoelectron Spectroscopy (XPS) was used to determine the valence state of gold in the synthesized nanoparticles 2•AuNPs, 3-AuNPs 4-AuNPs and 2'AuNPs. The samples were prepared by drop casting of the different AuNPs solutions $\left(\mathrm{CHCl}_{3}\right.$ or $\left.\mathrm{H}_{2} \mathrm{O}\right)$ onto a silicon substrate. 
For all experiments, sputtering of the samples was necessary to remove the outer organic layer and expose the metallic core so that the peaks corresponding to the $\mathrm{Au}^{0}$ could be clearly identified. The characteristic binding energies of $\mathrm{Au}^{0}$ at 84.4 and $88.2 \mathrm{eV}$, corresponding to $\mathrm{Au} 4 \mathrm{f}_{7 / 2}$ and $\mathrm{Au} 4 \mathrm{f}_{5 / 2}$ respectively, could be observed for 2•AuNPs, 3•AuNPs and 4AuNPs (see Supplementary Material Figure S30). In the case of the 2'•AuNPs it was not possible to observe the signals corresponding to $\mathrm{Au}^{0}$ not even after the sputtering step, probably because the coating tetrahydropyridine 2 . In the case of $\mathbf{2}^{\prime} \cdot$ AuNPs, 2 forms an extremely compact bilayer around the monolayer of the pyridinium salt, which difficult the extraction of the organic layer without completely destroying the sample.

Thermogravimetric Analysis (TGA). 2•AuNPs was further characterized by TGA, to confirm the presence of both ligands in these GNP. The thermogram of 2・AuNPs showed the presence of both 1.2Br and the correspondingly reduced 2 (see Supplementary Material Section 5 Figure S31). TGA also allowed determination of the mass ratio for the two ligands $(\mathbf{1} \cdot \mathbf{2 B r}$ and $\mathbf{2})$ and gold in the analysed 2.AuNPs samples, as stated in (Supplementary Material Table S4). Taking into account their respective molecular weights, we could determine the number of moles for each species, and establish a ratio of stabilizer to gold. Furthermore, considering the size of the gold core in $\mathbf{2}$ AuNPs, the number of gold moles per nanoparticle was determined, and with the ratio stabilizer: gold, the number of ligands per nanoparticle was calculated. Also, after calculating the nanoparticle's surface area the presence of ca. 14 molecules of $\mathbf{1 \cdot 2 B r}$ and 19 molecules of $\mathbf{2}$ per $\mathrm{nm}^{2}$ was estimated (see Supplementary Material Figure S31 and Table S4). This density is similar to the previously reported AuNPs incorporating gemini imidazolium amphiphiles as stabilizer agents.[22,25] Overall, it seems to confirm that the minority ligand $\mathbf{1} \cdot \mathbf{2 B r}$ forms a layer around the gold core, so that the formed $\mathbf{2}$ AuNPs have the positively charged pyridinium heads layer 
favouring stabilization of the gold core, and the tetrahydropyridine $\mathbf{2}$ forms a layer around the bispyridinium salt $\mathbf{1} \cdot \mathbf{2 B r}$. This particular disposition would explain why $\mathbf{1 \cdot 2 B r}$ could not be noticeably detected by MALDI-ToF MS and ${ }^{1} \mathrm{H}$ NMR spectroscopy.

\subsection{Cytotoxicity and genotoxicity assay of $1 \cdot 2 \mathrm{Br}, 2 \cdot$ AuNPs and $3 \cdot$ AuNPs}

The cytotoxicity and genotoxicity of ligand $\mathbf{1 \cdot 2 B r}$ as well as $\mathbf{2} \cdot \mathbf{A u N P s}$ and $\mathbf{3} \cdot \mathbf{A u N P s}$ were studied, since these AuNPs will be used later in the drug release study (see later). The cytotoxicity (expressed here as $\mathrm{IC}_{50}$ ) was determined in three different cell lines; the mouse fibroblast cell line (3T3/NIH), the human liver carcinoma cell line (HepG2) and the human epithelial colorectal adenocarcinoma cell line ( $\mathrm{CaCo}-2)$. The cells were exposed to a range of concentrations of ligand 1-2Br, 2-AuNPs and 3•AuNPs for $24 \mathrm{~h}$. The coated AuNPs after to interact with the cell medium, no agglomeration or turbidity was observed, indicating that the synthetized gold nanoparticles 2.AuNPs and 3-AuNPs were stably dispersed in the cell medium for the cytotoxicity test. After exposure, the viability of the cell culture was calculated using the MTT Assay, and the percentage of viable cells was determined as shown in the Supplementary Material Section 6 (Tables S5-S7). The $\mathrm{IC}_{50}$ concentration values calculated for ligand $\mathbf{1} \cdot \mathbf{2 B r}$ as well as for $\mathbf{2} \cdot \mathbf{A u N P s}$ and $\mathbf{3} \cdot \mathbf{A u N P s}$ are shown in Table 4. The $\mathrm{IC}_{50}$ values found from $\mathbf{2} \cdot \mathbf{A u N P s}$ and $\mathbf{3} \cdot \mathbf{A u N P s}$ were lower than the $\mathrm{IC}_{50}$ value obtained for the amphiphiles $\mathbf{1} \cdot \mathbf{2 B r}$ alone. These results suggests that the interaction of the polar head group with the gold nucleus of the nanoparticles prevents, in some way, a higher toxicity, presumably because the positive charge of the pyridinium salt is shielded from interaction with the cell.[37,38] In the case of $\mathbf{2} \cdot$ AuNPs, they were not cytotoxic for any cell line used, whereas 3·AuNPs showed very low toxicity in HepG2 and CaCo-2 at high concentrations (418 $\mu \mathrm{M}$ and $10460 \mu \mathrm{M}$, respectively). Comparison of the values found in the literature for cytotoxicity of gold nanoparticles is hampered by the different experimental protocols reported for its 
evaluation, as well as for the differences in the composition of the nanomaterials, for which a precise composition is not always defined.[39] Several reports indicate that interaction with the biological media depends on many factors, such as size, shape and charge of gold nanoparticles.[40] Additionally, the moderate toxicity of cationic particles has been evaluated,[41] with the toxicity mainly attributed to the cationic surfactant used as coating agent.[42]

Table 4. Values of the $\mathrm{IC}_{50}$ determined for the products tested in three different cell lines.

\begin{tabular}{|c|c|c|c|c|c|c|}
\hline \multirow[b]{2}{*}{ Products } & \multicolumn{2}{|c|}{ Cell line 3T3 } & \multicolumn{2}{|c|}{ Cell line HepG2 } & \multicolumn{2}{|c|}{ Cell line $\mathrm{CaCo-2}$} \\
\hline & $\begin{array}{c}\mathrm{IC}_{50} \\
(\mu \mathrm{g} / \mathrm{mL})\end{array}$ & $\begin{array}{l}\mathrm{IC}_{50} \\
(\mu \mathrm{M})\end{array}$ & $\begin{array}{c}\text { IC50 } \\
(\mu \mathrm{g} / \mathrm{mL})\end{array}$ & $\begin{array}{l}\mathrm{IC}_{50} \\
(\mu \mathrm{M})\end{array}$ & $\begin{array}{c}\text { IC50 } \\
(\mu \mathrm{g} / \mathrm{mL})\end{array}$ & $\begin{array}{l}\text { IC50 } \\
(\mu \mathrm{M})\end{array}$ \\
\hline $1 \cdot 2 \mathrm{Br}$ & 250 & 96 & 70 & 73 & $>500$ & 1833 \\
\hline $2 \cdot$ AuNPs & $>500$ & $>500$ & $>500$ & $>500$ & $>500$ & $>500$ \\
\hline 3·AuNPs & $>500$ & $>500$ & 611 & 418 & $>500$ & 10460 \\
\hline
\end{tabular}

The maximum concentration tested was $500 \mu \mathrm{g} / \mathrm{mL}$. Table (1.5-column)

To be suitable for drug delivery purposes, the carriers themselves must be biocompatible and present low toxicity. In our work, it was found that these AuNPs (2・AuNPs and 3·AuNPs), showed low toxicity in three studied cell lines, since the values found for the $\mathrm{IC}_{50}$ were $c a .0 .5-1 \mathrm{mM}$. These are very high values taking into consideration they are well above the expected concentrations to be administered, which means that the AuNPs should be safe.

Additionally, to evaluate the genotoxicity of $1 \cdot 2 \mathrm{Br}, 2 \cdot \mathbf{A u N P s}$ and $3 \cdot$ AuNPs in three cell line (3T3/NIH, HepG2 and CaCo-2), the Single Cell Gel Electrophoresis, also known as Comet Assay, was used according to guidelines.[43] For this analysis, cell viability higher than $70 \%$ was 
required and a genotoxic effect was considered for tail intensity values higher than $10 \%$. The DNA-damaging alkylating-agent methylmethane sulfonate (MMS $400 \mathrm{mM}$ ) was used as positive control. Table S5-S7 in the Supplementary Material show the percentage of tail intensity referring to the DNA fragmentation in the presence of amphiphile $\mathbf{1} \cdot \mathbf{2 B r}, \mathbf{2} \cdot \mathbf{A u N P s}$ and $\mathbf{3} \cdot \mathbf{A u N P s}$, at the same range of concentrations used for testing their cytotoxicity. It was observed that neither $\mathbf{1} \cdot \mathbf{2 B r}$ nor the AuNPs (2•AuNPs and 3-AuNPs) show any significant formation of a tail of cellular DNA fragments within the studied concentrations and cell lines tested, which means that below the $\mathrm{IC}_{50}$ no genotoxicity is observed (see Supplementary Material Tables S5-S7), confirming the suitability of these nanomaterials for drug delivery purposes.

\subsection{Incorporation of ibuprofen and piroxicam into different AuNPs (organic and water soluble)}

Prior to the incorporation study of ibuprofen and piroxicam into different AuNPs was study the complexation ability of the bis-pyridinium amphiphile $\mathbf{1} \cdot \mathbf{2 B r}$ to ibuprofen and piroxicam was examined in solution, using ${ }^{1} \mathrm{H}$ NMR spectroscopy. The binding of $\mathbf{1} \cdot \mathbf{2 B r}$ with piroxicam appears to be the stronger as indicated by the observed chemical shifts (see Supplementary Material Section 7 Figure S32 and Table S8).

The synthesis of 5•AuNPs and 6•AuNPs (see Supplementary Material Section 8 Figure S33) was necessary to use as control nanoparticles in the incorporation study of drugs such as ibuprofen, piroxicam and their respective sodium salts (see later). In both cases, the obtained $\mathbf{5} \cdot \mathbf{A u N P s}$ and 6. AuNPs display a spheroidal shape and low polydispersity (Figure S34 and Table S9 in the Supplementary Material Section 8). 
After evaluation of the anion binding exhibited by the pyridinium salt $\mathbf{1 \cdot 2 B r}$, we decided to investigate if the binding ability was still operating in the AuNPs prepared in this work. Initially, the anion binding properties of $\mathbf{2} \cdot \mathbf{A u N P s}, \mathbf{3} \cdot \mathbf{A u N P s}, \mathbf{4} \cdot \mathbf{A u N P s}$, as well as the non-pyridinium containing controls $5 \cdot$ AuNPs and 6•AuNPs were studied by UV-vis absorption spectroscopy. The quantification of ibuprofen and piroxicam were carried out by UV-vis absorption spectroscopy, and used to evaluate the incorporation of these drugs into water soluble 3·AuNPs and 5•AuNPs; their corresponding sodium salts (ibuprofen sodium salt and piroxicam sodium salt), were incorporated into organic-soluble $2 \cdot$ AuNPs, $4 \cdot$ AuNPs and $5 \cdot$ AuNPs.

The results of drug incorporation in different nanoparticles are shown in Table 5. Control extraction experiments using only solvent as the extraction phase (without any nanoparticles) indicated that, the quantity of drug in solution was similar to that obtained in the initial solution. These results indicated that the solvent $\left(\mathrm{H}_{2} \mathrm{O} / \mathrm{CHCl}_{3}\right)$ does not interfere with the incorporation of drugs into nanoparticles.

In the case of $\mathbf{2}$ AuNPs (organic-soluble AuNPs), the percentage of piroxicam sodium salt incorporated to them was greater than ibuprofen sodium salt (Table 5), possibly because of the higher affinity between piroxicam sodium salt and the ligand $\mathbf{1 \cdot 2 B r}$ as the study of drug-ligand interaction by NMR had shown.

A similar trend is observed for the AuNPs with both ligand $\mathbf{1} \cdot \mathbf{2} \mathbf{B r}$ and the pegylated thiol (3·AuNPs and 4-AuNPs), which showed higher values of incorporated piroxicam or piroxicam sodium salt rather than either ibuprofen or its sodium salt.

At this point, a control was performed with nanoparticles $5 \cdot$ AuNPs and $6 \cdot A u N P s$, incorporating only the pegylated thiol, but not the gemini-pyridinium salt $\mathbf{1 \cdot 2 B r}$. The incorporation of the piroxicam drug was evaluated showing extremely low percentages of incorporation in both 
nanoparticles 5-AuNPs and 6-AuNPs with values of 8 and $25 \%$, respectively, indicating that $\mathbf{1} \mathbf{2 B r}$ present in the nanoparticles is by far the main responsible for the incorporation of the drug in the nanoparticles synthesized 2•AuNPs, 3·AuNPs and 4·AuNPs.

Table 5. Percentages of anionic drug incorporated in different gold nanoparticles.

\begin{tabular}{|c|c|c|c|c|}
\hline \multirow[b]{2}{*}{ AuNPs } & \multicolumn{4}{|c|}{ Drug incorporation $(\%)^{\mathrm{n}}$} \\
\hline & $\begin{array}{c}\text { Ibuprofen } \\
\text { (sodium salt) }\end{array}$ & Ibuprofen & $\begin{array}{l}\text { Piroxicam } \\
\text { (sodium salt) }\end{array}$ & Piroxicam \\
\hline 2•AuNPs (a) & $13.6 \pm 4.0$ & $\mathrm{n} / \mathrm{d}$ & $46.3 \pm 2.3$ & $\mathrm{n} / \mathrm{d}$ \\
\hline 3·AuNPs (b) & $\mathrm{n} / \mathrm{d}$ & $19.3 \pm 2.6$ & $\mathrm{n} / \mathrm{d}$ & $78.3 \pm 4.0$ \\
\hline 4·AuNPs (a) & $17.0 \pm 3.0$ & $\mathrm{n} / \mathrm{d}$ & $73.6 \pm 3.9$ & $\mathrm{n} / \mathrm{d}$ \\
\hline
\end{tabular}

Accordingly, the bis-pyridinium salt $\mathbf{1} \cdot \mathbf{2 B r}$ containing nanoparticles $\mathbf{3} \cdot$ AuNPs (water-soluble) and 4-AuNPs (organic-soluble) were used for in vitro studies of piroxicam or piroxicam sodium salt. In order to know the concentration of 3-AuNPs and 4-AuNPs we applied calculations described by Haiss (see Supplementary Material Section 9).[44] The final concentration of 3·AuNPs was $170 \mathrm{nM}$, and $143 \mathrm{nM}$ from $4 \cdot$ AuNPs. After the extraction, in the case of $\mathbf{3} \cdot$ AuNPs the aqueous phase was washed three times with dichloromethane and in the case of $\mathbf{4} \cdot \mathbf{A u N P s}$ the organic phase was washed three times with water, to remove any unbound drug (piroxicam and piroxicam sodium salt). The aqueous phase with the 3-AuNPs and piroxicam incorporated exhibits, besides the 3.AuNPs peak at $522 \mathrm{~nm}$, the peak at $342 \mathrm{~nm}$ corresponding to piroxicam (see Supplementary 
Material Figure S35 a)). This peak was not visible in the organic phases used to extract piroxicam from the nanoparticles. On the other hand, from the organic phase with the 4-AuNPs and piroxicam sodium salt incorporated exhibits, besides the $4 \cdot A u N P s$ peak at $528 \mathrm{~nm}$, the peak at 324 $\mathrm{nm}$ corresponding to piroxicam (see Supplementary Material Figure S35 b)). This peak was not visible in the aqueous phases used to extract the piroxicam sodium salt from the nanoparticles. This means that the drug was well incorporated into the nanoparticles, and that the pyridinium ligands can bind enolate incorporating compounds. Also, a slight change in the SPR peak of the AuNPs was registered, that initially was at $518 \mathrm{~nm}$ and shifted to $522 \mathrm{~nm}$ for 3•AuNPs and 519 $\mathrm{nm}$ and shifted to $528 \mathrm{~nm}$ for $\mathbf{4} \cdot \mathrm{AuNPs}$. It is known that the SPR peak depends not only of the size of the AuNPs but also of the ligand that is covering the AuNPs, so we could explain this shift because of the incorporation of the drug (piroxicam and its sodium salt) in the structure. According to our calculations, we could incorporate $50 \mu \mathrm{g}$ of piroxicam $/ \mathrm{mg}$ in 3·AuNPs and $46 \mu \mathrm{g}$ of piroxicam sodium salt $/ \mathrm{mg}$ in $\mathbf{4} \cdot \mathbf{A u N P s}$.

Finally, the stability of the water soluble $3 \cdot$ AuNPs after the incorporation of piroxicam was studied for a period of three months, and no macroscopic changes in the colloidal dispersions or variations in the SPR band were observed, which indicates that their stability was not affected after the incorporation of the drug (see in the Supplementary Material Table S10).

\subsection{In vitro release studies}

The release of piroxicam from the AuNPs was determined using a Franz cells system as schematic representation is included in Figure S36 in the Supplementary Material Section 1.[45] The samples were suspended in Sorensen buffer at either pH 5.5 or 7.4, to simulate physiological conditions, and the receptor solution used was $\mathrm{NaOH} 71 \mathrm{mM}$, in which piroxicam is soluble, as tested prior to the experiments, and thus complying with the SINK conditions. Given the size of the gold 
nanoparticles, dialysis membranes were selected with a cut-off which allows the passage of piroxicam (molecular weight $331.35 \mathrm{Da}$ ) but prevents the passage of the nanoparticles (membrane dialysis pore diameter is equivalent to $2.4 \mathrm{~nm}$ ).

Six different kinetic models (zero order, first order, Plateau followed by a first order, KorsmeyerPeppas, Higuchi and Weibull function) were used to fit the experimental data obtained in the drug release experiments following the corresponding equations (see Table S11 in the Supplementary Material). The kinetic model that best describes the release of piroxicam and sodium salt piroxicam respectively, from 3·AuNPs and $\mathbf{4} \cdot \mathrm{AuNPs}$, for both $\mathrm{pH}$ values tested, is the Plateau followed by a first order model as shown in Figure S37 in the Supplementary Material. This means that the release rate depends only on the amount of drug present. Furthermore, the presence of a delay in the beginning of the release means that the drug is well encapsulated by the ligand $\mathbf{1} \cdot \mathbf{2} \mathbf{B r}$, and suffers other diffusion processes from the interior of the nanoparticle, specifically a partition between the inner environment and the donor solution. This partition favours the slow release of the drug, because the donor solution must comply with the physiological conditions, opposite to the receptor solution. Additionally, is know that the piroxicam is more soluble in aqueous solution at $\mathrm{pH} 7.4$ (similar to physiological conditions) than in solutions at acidic $\mathrm{pH}$, which is favoured by the ionization of the drug at $\mathrm{pH}$ 7.4.[46] This intrinsic characteristic of the drug does not favour the diffusion process from the interior of the nanoparticle, resulting in a delayed release of the drug at $\mathrm{pH} 5.5$ respect to 7.4 .

At physiological conditions the drug release followed a first order kinetics (Figure 4), with values of the dissociation constant $K_{D}$ of $0.0129 \mathrm{~h}^{-1}$ and $0.0100 \mathrm{~h}^{-1}$ from 3·AuNPs and 4.AuNPs, respectively. At pH 5.5, the same kinetics were observed, and the dissociation constant found were $0.0095 \mathrm{~h}^{-1}$ and $0.0034 \mathrm{~h}^{-1}$ from 3·AuNPs and $4 \cdot$ AuNPs, respectively. 
Additionally, the amodelistic parameters (efficiency, medium dissolution time (MDT) and area under curve (AUC)) were calculated (Supplementary Material Section 10, Table S12). Therefore, Student's t-test analysis was performed and significant differences were found between the releases at the pH 5.5 and 7.4 (see Supplementary Material Table S13). At pH 7.4 the efficiency of the release is higher than at pH 5.5 in both AuNPs (3-AuNPs and 4-AuNPs), meaning that it is more suited for delivery under physiological conditions and not for an external application in the skin since a higher amount of drug can be released from the AuNPs. On the other hand, the value of MDT registered at $\mathrm{pH} 7.4$ is lower, suggesting that the release of this drug from the AuNPs complex is favoured at this $\mathrm{pH}$. Moreover, in the case of the water-soluble 3·AuNPs the release of the drug is more favoured than $4 \cdot$ AuNPs. This can be seen as an advantage of $\mathbf{3} \cdot$ AuNPs, allowing its use as nanosystems with a high potential for use in biomedical applications.

a)

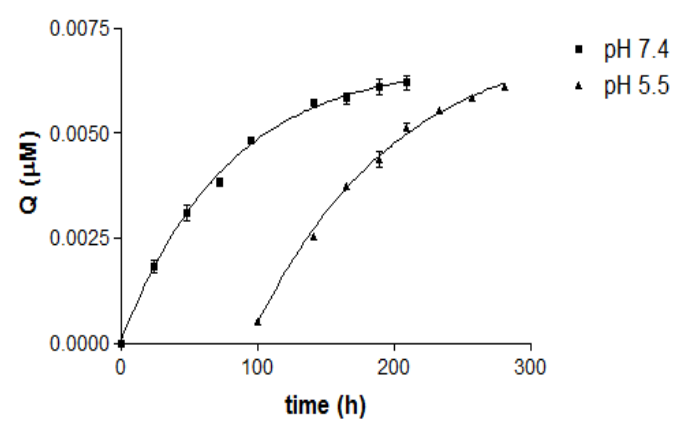

b)

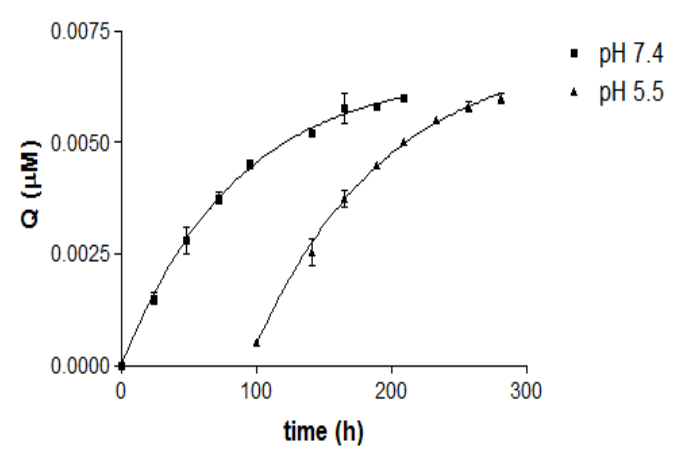


Figure 4. a) Liberation profile at $\mathrm{pH} 7.4$ and 5.5 of piroxicam-3·AuNPs, b) Liberation profile at pH 7.4 and 5.5 of piroxicam sodium salt-4 AuNPs. Results displayed as an average with error bars corresponding to standard deviation obtained for $n=3$ independent experiments.

Figure (1.5-column)

Additionally, two stability experiments in aqueous solution of 3·AuNPs before and after the incorporation of piroxicam were performed for a period of a week. The piroxicam-3·AuNPs were dissolved in three buffer solutions at either $\mathrm{pH} \mathrm{5.5,} 7.4$ and 9, at room temperature and at $37^{\circ} \mathrm{C}$. Any case no macroscopic changes in the colloidal dispersions or variations in the SPR band and in the corresponding band of the drug were observed, which indicates that the 3·AuNPs are stable at different $\mathrm{pH}$ under the described conditions and they were not affected after the incorporation of the drug (see in the Supplementary Material Section 11 Tables S14 and S15, respectively). Obviously, the complex would be coated AuNPs-piroxicam will be no longer existing when upon release conditions (see above, in vitro release studies).

\section{Conclusions}

In this work, we have synthesized and characterized three bis-pyridinium salts $\mathbf{1} \cdot \mathbf{2 B r}, \mathbf{3} \cdot \mathbf{2 B r}$, and 4-2Br with different chain lengths $(18,10$ and 1 carbon atoms, respectively). Clearly, the length of the chain of the bis-pyridinium salt, is decisive for the amphiphile to act as promoter agent, since only $\mathbf{1} \cdot \mathbf{2 B r}$ containing 18 carbon atom chains are able to successfully generate $\mathbf{2} \cdot \mathbf{A u N P s}$ following a biphasic method.[30] Consequently, the use of $\mathbf{3} \cdot \mathbf{2 B r}$ and $\mathbf{4} \cdot \mathbf{2 B r}$ for the synthesis of AuNPs is not favourable. The tetrahydropyridine moiety in $\mathbf{2}$ (resulting from the reduction of $\mathbf{1 \cdot 2 B r}$ ) is capable of reducing $\mathrm{Au}^{+3}$ to $\mathrm{Au}^{0}$, due to its spontaneous oxidation to the pyridinium salt, leading to the formation of $\mathbf{2}^{\prime} \cdot \mathbf{A u N P s}$. The gold nanoparticles synthesized $\mathbf{1} \cdot \mathbf{A u N P s}-\mathbf{4} \cdot \mathbf{A u N P s}$ and $\mathbf{2}^{\prime}$-AuNPs proved stable and to have low polydispersity. Remarkably, $\mathbf{2}^{\prime} \cdot$ AuNPs were found 
to be stable and monodisperse only when synthesized in the presence of $\mathrm{KBr}$, indicating not only how crucial are the long chains in the amphiphile but the critical role of anions in their structure for the synthesis and stability of these nanoparticles, as described in previous report.[22,33] The close proximity of the ligand $\mathbf{1 \cdot 2 B r}$ to the metallic core was confirmed by different techniques such as MALDI-ToF MS and NMR spectroscopy. The ligand $\mathbf{1 \cdot 2 B r}$ as well as $\mathbf{2} \cdot \mathbf{A u N P s}$ and 3-AuNPs were neither cytotoxic nor genotoxic to the cell lines studied (3T3/NIH, HepG2 and $\mathrm{CaCo}-2)$ at the concentrations tested, when compared with similar structures using the same cell lines.[23] Additionally, 3·AuNPs and 4·AuNPs incorporating both $\mathbf{1} \cdot \mathbf{2 B r}$ and $\mathrm{HS}-\mathrm{C}_{11}-(\mathrm{EG})_{6}-\mathrm{OH}$ encapsulate piroxicam and piroxicam sodium salt, and release it in a sustained manner, suggesting that it diffuses from the complex instead of being released with an initial burst. This means that these vehicles could be used for long-term delivery of the drug. Moreover, the incorporation of piroxicam was evaluated and showed extremely low percentages of incorporation in both nonpyridinium coated nanoparticles 5-AuNPs and 6-AuNPs, indicating that the bis-pyridinium functionalization present in $\mathbf{2} \cdot$ AuNPs, 3.AuNPs and $\mathbf{4} \cdot \mathbf{A u N P s}$ is by far the main factor determining the incorporation of the drug. Additionally, 3·AuNPs and 4·AuNPs showed the ability to incorporate piroxicam and piroxicam sodium salt respectively, with no significant differences in the amount of drug encapsulated. Moreover,the in vitro release of 3·AuNPs and 4-AuNPs at two different $\mathrm{pH}$ values (7.4 and 5.5) proves a faster release profile at $\mathrm{pH} 7.4$, indicating their suitability as promising materials for delivery in physiological conditions. Finally, 3-AuNPs resulted stable at different $\mathrm{pH}$ under the described conditions and they were not affected after the incorporation of the drug. The next step in this research would be incorporation of other anionic drugs of higher therapeutic interest and testing the in vivo efficacy through alternative to oral administration in order to convert the AuNPs from a delivery vehicle into a theranostics tool. 


\section{Disclosures}

We have no conflicts of interest.

\section{Acknowledgment}

This work was supported by the EU ERDF (FEDER) funds and MINECO trough Spanish Government [grant TEC2014-51940-C2-2-R]. M.E.A-R thanks the Universitat de Barcelona for a predoctoral grant (APIF).

\section{Appendix A. Supplementary material}

Supplementary data associated with this article can be found, in the online version, at http://dx.doi.org/10.1016/j.jcis.xxxx.xx.xxx.

\section{References}

[1] M.-C.C. Daniel, D. Astruc, Gold Nanoparticles: Assembly, Supramolecular Chemistry, Quantum-Size-Related Properties, and Applications toward Biology, Catalysis, and Nanotechnology, Chem. Rev. 104 (2004) 293-346.

[2] H. Hakkinen, The gold-sulfur interface at the nanoscale, Nat Chem. 4 (2012) 443-455.

[3] B. Hvolbæk, T.V.W. Janssens, B.S. Clausen, H. Falsig, C.H. Christensen, J.K. Nørskov, Catalytic activity of Au nanoparticles, Nano Today 2 (2007) 14-18.

[4] Y. Mikami, A. Dhakshinamoorthy, M. Alvaro, H. Garcia, Catalytic activity of unsupported gold nanoparticles, Catal. Sci. Technol. 3 (2013) 58-69.

[5] X. Huang, M.A. El-Sayed, Gold nanoparticles: Optical properties and implementations in cancer diagnosis and photothermal therapy, J. Adv. Res. 1 (2010) 13-28.

[6] K. Saha, S.S. Agasti, C. Kim, X. Li, V.M. Rotello, Gold Nanoparticles in Chemical and Biological Sensing, Chem. Rev. 112 (2012) 2739-2779.

[7] P. Ghosh, G. Han, M. De, C.K. Kim, V.M. Rotello, Gold nanoparticles in delivery applications, Adv. Drug Deliv. Rev. 60 (2008) 1307-1315.

[8] T. Stuchinskaya, M. Moreno, M.J. Cook, D.R. Edwards, D.A. Russell, Targeted photodynamic therapy of breast cancer cells using antibody-phthalocyanine-gold nanoparticle conjugates, Photochem. Photobiol. Sci. 10 (2011) 822-831.

[9] Z. Wang, L. Ma, Gold nanoparticle probes, Coord. Chem. Rev. 253 (2009) 1607-1618.

[10] I. Hussain, S. Graham, Z. Wang, B. Tan, D.C. Sherrington, S.P. Rannard, A.I. Cooper, M. Brust, Size-Controlled Synthesis of Near-Monodisperse Gold Nanoparticles in the 1-4 nm Range Using Polymeric Stabilizers, J. Am. Chem. Soc. 127 (2005) 16398-16399. 
[11] X. Shi, T.R. Ganser, K. Sun, L.P. Balogh, J.R. Baker, Characterization of crystalline dendrimer-stabilized gold nanoparticles, Nanotechnology 17 (2006) 1072-1078.

[12] S. Si, E. Dinda, T.K. Mandal, In situ synthesis of gold And silver nanoparticles by using redox-active amphiphiles and their phase transfer to organic solvents, Chem. Eur. J. 13 (2007) 9850-9861.

[13] R. Lévy, N.T.K. Thanh, R.C. Doty, I. Hussain, R.J. Nichols, D.J. Schiffrin, M. Brust, D.G. Fernig, Rational and Combinatorial Design of Peptide Capping Ligands for Gold Nanoparticles, J. Am. Chem. Soc. 126 (2004) 10076-10084.

[14] D. Pissuwan, T. Niidome, M.B. Cortie, The forthcoming applications of gold nanoparticles in drug and gene delivery systems, J. Control. Release. 149 (2011) 65-71.

[15] J. Dupont, M.R. Meneghetti, On the stabilisation and surface properties of soluble transition-metal nanoparticles in non-functionalised imidazolium-based ionic liquids, Curr. Opin. Colloid Interface Sci. 18 (2013) 54-60.

[16] V.J. Gandubert, R.B. Lennox, Assessment of 4-(Dimethylamino)pyridine as a Capping Agent for Gold Nanoparticles, Langmuir 21 (2005) 6532-6539.

[17] S.K. Ghosh, Spectroscopic evaluation of 4-(dimethylamino)pyridine versus citrate as stabilizing ligand for gold nanoparticles, Colloids Surfaces A Physicochem. Eng. Asp. 371 (2010) 98-103.

[18] D.I. Gittins, F. Caruso, Spontaneous phase transfer of nanoparticulate metals from organic to aqueous media, Angew. Chem. Int. 40 (2001) 3001-3004.

[19] C. Zapata-Urzúa, M. Pérez-Ortiz, G.A. Acosta, J. Mendoza, L. Yedra, S. Estradé, A. Álvarez-Lueje, L.J. Núñez-Vergara, F. Albericio, R. Lavilla, M.J. Kogan, Hantzsch dihydropyridines: Privileged structures for the formation of well-defined gold nanostars, J. Colloid Interface Sci. 453 (2015) 260-269.

[20] R. Li, K. Wu, C. Liu, Y. Huang, Y. Wang, H. Fang, H. Zhang, C. Li, 4-Amino-1-(3mercapto-propyl)-pyridine Hexafluorophosphate Ionic Liquid Functionalized Gold Nanoparticles for IgG Immunosensing Enhancement, Anal. Chem. 86 (2014) 5300-5307.

[21] K.B. Male, J.J. Li, C.C. Bun, S.C. Ng, J.H.T. Luong, Synthesis and stability of fluorescent gold nanoparticles by sodium borohydride in the presence of mono-6-deoxy-6-pyridiniumbeta-cyclodextrin chloride, J. Phys. Chem. C. 112 (2008) 443-451.

[22] L. Casal-Dujat, M. Rodrigues, A. Yagüe, A.C. Calpena, D.B. Amabilino, J. GonzálezLinares, M. Borràs, L. Pérez-García, Gemini imidazolium amphiphiles for the synthesis, stabilization, and drug delivery from gold nanoparticles, Langmuir 28 (2012) 2368-2381.

[23] E. Amirthalingam, M. Rodrigues, L. Casal-Dujat, A.C. Calpena, D.B. Amabilino, D. Ramos-López, L. Pérez-García, Macrocyclic imidazolium-based amphiphiles for the synthesis of gold nanoparticles and delivery of anionic drugs, J. Colloid Interface Sci. 437 (2015) 132-139.

[24] L. Casal-Dujat, Doctoral Thesis - Soft Nanomaterials from bis-imidazolium amphiphiles, phdthesis, University of Barcelona, 2010.

[25] M. Rodrigues, A.C. Calpena, D.B. Amabilino, D. Ramos-López, J. de Lapuente, L. Pérez- 
García, Water-soluble gold nanoparticles based on imidazolium gemini amphiphiles incorporating piroxicam, RSC Adv. 4 (2014) 9279-9287.

[26] R. van Haselen, P. Fisher, A randomized controlled trial comparing topical piroxicam gel with a homeopathic gel in osteoarthritis of the knee., Rheumatology 39 (2000) 714-719.

[27] All the images were treated with the Image J program (http://rsbweb.nih.gov/ij).

[28] E. Alcalde, L. Pérez-García, I. Dinarés, J. Frigola, An efficient synthesis of 2vinylbenzimidazoles from 1-(2-(benzimidazol-2-ylethyl) pyridinium salts using an anionexchange resin, J. Org.Chem. 56 (1991) 6516-6521.

[29] J. Turkevich, P.C. Stevenson, J. Hillier, A study of the nucleation and growth processes in the synthesis of colloidal gold, Discuss. Faraday Soc. 11 (1951) 55-75.

[30] M. Brust, M. Walker, D. Bethell, D.J. Schiffrin, R. Whyman, Synthesis of thiol-derivatised gold nanoparticles in a two-phase Liquid-Liquid system, J. Chem. Soc. Chem. Commun. (1994) 801-802.

[31] N.C.C. Meng Yang Chang, Shui Tein Chen, An Eficient Synthesis of N-Alkyl-4-substituted 3H-Pyridine-2,6-dione. Synthesis of Isoguvacine and MDL-11,939, Heterocycles 57 (2002) 2321-2334.

[32] R.E. Lyle, C.B. Boyce, Sodium borohydride reduction of sterically hindered pyridinium salts, J. Org. Chem. 39 (1974) 3708-3711.

[33] J. Fink, C.J. Kiely, D. Bethell, D.J. Schiffrin, Self-organization of nanosized gold particles, Chem. Mater. 10 (1998) 922-926.

[34] E. Oh, K. Susumu, R. Goswami, H. Mattoussi, One-phase synthesis of water-soluble gold nanoparticles with control over size and surface functionalities, Langmuir 26 (2010) 76047613.

[35] T.K. Sarma, D. Chowdhury, A. Paul, A. Chattopadhyay, Synthesis of Au nanoparticle conductive polyaniline composite using $\mathrm{H}_{2} \mathrm{O}_{2}$ as oxidising as well as reducing agent, Chem. Commun. (2002) 1048-1049.

[36] Q. Li, B. Lu, L. Zhang, C. Lu, Synthesis and stability evaluation of size-controlled gold nanoparticles via nonionic fluorosurfactant-assisted hydrogen peroxide reduction, J. Mater. Chem. 22 (2012) 13564-13570.

[37] B.O. and B.J. F. Stock, J. Hoffmann, J. Ranke, R. Störmann, B. Jastorffa, Effects of Ionic Liquids on the Acetylcholinesterase - A Structure-Activity Relationship Consideration, Green Chem. 6 (2004) 286-290.

[38] D.J. Couling, R.J. Bernot, K.M. Docherty, J.K. Dixon, E.J. Maginn, Assessing the factors responsible for ionic liquid toxicity to aquatic organisms via quantitative structure-property relationship modeling, Green Chem. 8 (2006) 82-90.

[39] N. Khlebtsov, L. Dykman, Biodistribution and Toxicity of Engineered Gold Nanoparticles: A Review of in Vitro and in Vivo Studies, Chem. Soc. Rev. 40 (2011) 1647-1671.

[40] N.M. Schaeublin, L.K. Braydich-Stolle, A.M. Schrand, J.M. Miller, J. Hutchison, J.J. Schlager, S.M. Hussain, Surface charge of gold nanoparticles mediates mechanism of toxicity, Nanoscale 3 (2011) 410-420. 
[41] C.M. Goodman, C.D. McCusker, T. Yilmaz, V.M. Rotello, Toxicity of Gold Nanoparticles Functionalized with Cationic and Anionic Side Chains, Bioconjug. Chem. 15 (2004) 897900.

[42] E.E. Connor, J. Mwamuka, A. Gole, C.J. Murphy, M.D. Wyatt, Gold Nanoparticles Are Taken Up by Human Cells but do not Cause Acute Cytotoxicity, Small 1 (2005) 325-327.

[43] ASTM-E2186."Standard Guide for Determining DNA Single-Strand Damage in Eukaryotic Cells using the Comet Assay," (2003).

[44] W. Haiss, N.T.K. Thanh, J. Aveyard, D.G. Fernig, Determination of size and concentration of gold nanoparticles from UV-vis spectra., Anal. Chem. 79 (2007) 4215-4221.

[45] M.E. Morales, V. Gallardo Lara, A.C. Calpena, J. Doménech, M.A. Ruiz, Comparative study of morphine diffusion from sustained release polymeric suspensions, J. Control. Release. 95 (2004) 75-81.

[46] M.F. Abdulkarim, G.Z. Abdullah, M. Chitneni, I.M. Salman, O.Z. Ameer, M.F. Yam, E.S. Mahdi, M.A. Sattar, M. Basri, A.M. Noor, Topical piroxicam in vitro release and in vivo anti-inflammatory and analgesic effects from palm oil esters-based nanocream., Int. J. Nanomedicine. 5 (2010) 915-924. 